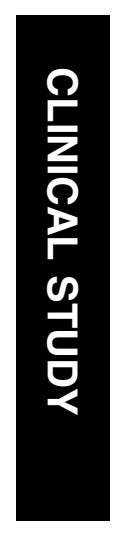

\title{
Impact of \\ symptomatic dry eye on vision-related daily activities: The Singapore Malay Eye Study
}

${ }^{1}$ Singapore National Eye Center, Singapore

${ }^{2}$ Singapore Eye Research Institute, Singapore

${ }^{3}$ Department of Community, Occupational and Family Medicine, Yong Loo Lin School of Medicine, National University of Singapore, Singapore

${ }^{4}$ Center for Eye Research Australia, University of Melbourne, Melbourne, Victoria, Australia

${ }^{5}$ Department of Ophthalmology, Yong Loo Lin School of Medicine, National University of Singapore, Singapore

${ }^{6}$ Center for Vision Research, University of Sydney, Sydney, New South Wales, Australia

Correspondence: L Tong, Department of Ophthalmology, Singapore National Eye Center, 11 Third Hospital Avenue, Singapore 168751 Singapore

Tel: + 659818 6221; Fax: + 6563224599 .

E-mail: Louis.tong.h.t@ snec.com.sg

Received: 21 January 2010 Accepted in revised form: 5 April 2010

Published online: 21 May 2010

\section{Abstract}

Purpose To examine the impact of symptomatic dry eye on vision-related daily activities.

Methods A population-based survey of eye diseases was conducted on $\mathbf{3 2 8 0} \mathbf{( 7 8 . 7 \%}$ response rate) Malay persons aged $\geqslant 40$ years, who were randomly selected from designated areas in southwestern Singapore. Participants were administered a standardized dry eye questionnaire consisting of six questions on symptoms, a questionnaire on vision-related daily activities, and underwent a comprehensive systemic and ocular examination. Symptomatic dry eye was defined as one or more self-reported symptoms that were frequently present (ranked as often or all the time). Logistic regression method was used to examine the relationship of symptomatic dry eye with difficulty in performing daily activities.

Results In adults without visual impairment, symptomatic dry eye after adjusting for age, gender, and presenting visual acuity was significantly associated with difficulty in vision-related activities such as navigating stairs (odds ratio $(O R)=1.96,95 \%$ confidence interval (CI): 1.28-3.00), recognizing friends $(O R=1.99$, 95\% CI: 1.45-2.73), reading road signs $(O R=1.87,95 \% C I$ : $1.36-2.57)$, reading newspaper (OR $=1.50,95 \% \mathrm{CI}$ : 1.11-2.04), watching television $(\mathrm{OR}=1.90,95 \% \mathrm{CI}$ : 1.26-2.87), cooking $(\mathrm{OR}=1.94,95 \% \mathrm{CI}$ : 1.02-3.71), and driving at night $(O R=2.06$, 95\% CI: 1.32-3.21).

Conclusion Symptomatic dry eye was associated with difficulty in performing vision-dependent tasks, independent of visual acuity and other factors. These findings have public health significance and suggest that
L Tong ${ }^{1,2}$, S Waduthantri ${ }^{1,2}$, TY Wong ${ }^{1,2,3,4,5}$, SM Saw ${ }^{2,3}$, JJ Wang ${ }^{4,6}$, M Rosman $^{1,2}$ and E Lamoureux ${ }^{4}$ the visual dysfunction in dry eye should be further characterized.

Eye (2010) 24, 1486-1491; doi:10.1038/eye.2010.67; published online 21 May 2010

Keywords: dry eye; human; epidemiology; vision ; cross-sectional study questionnaire

\section{Introduction}

Dry eye is a common eye condition due to diminished tear production or increased tear evaporation, which results in ocular surface dysfunction, ${ }^{1,2}$ and a typical spectrum of symptoms including burning or stinging, tearing, foreign-body sensation, photophobia, and blurred vision. ${ }^{3-5}$ The prevalence of symptomatic dry eye has been estimated to be between 15-33\% in adult populations and is thought to be more common in elderly and females, and possibly Asians. ${ }^{6}$ In the United States, the cost of managing and treating dry eye patients in healthcare organizations is $\$ 700000$ per million patients. ${ }^{6}$

Dry eye is known to affect the quality of vision because of the irregularity of the tear film and the optical refracting surfaces associated with this condition. ${ }^{7,8}$ Some studies suggest that severe symptomatic dry eye could result in a decreased ability to perform daily activities, thus having an impact on the quality of life..$^{9-11}$ However, these studies have been largely confined to clinical trials involving relatively small sample sizes and selected patient groups, ${ }^{7-13}$ and the impact of dry eye on specific daily tasks and visual function in the general population remains unclear. In this study, we report the impact of symptomatic dry eye on vision-related daily activities in a large 
population-based study of Southwestern Asian Malay adults in Singapore.

\section{Materials and methods}

\section{Study population}

The Singapore Malay Eye Study was a population-based survey of Malay adults living in Singapore. The methodology has been published elsewhere. ${ }^{14}$ The sampling frame consisted of all Malays aged 40-79, living in designated study areas in southwestern Singapore. From a list of 16069 names provided by the Ministry of Home Affairs, age-stratified random sampling was used to select 5600 names (1400 people from each decade of 40-49, 50-59, 60-69, 70-79 years). Out of the initial 5600 names, 4168 participants (74.4\%) were determined to be eligible to participate based on pre-specified criteria. ${ }^{12}$ Out of this, 3280 individuals participated in the study, giving an overall response rate of $78.7 \%$ eligible participants. The participants $(n=3280)$ and non-participants $(n=888)$ did not differ in their gender composition $(P=0.821)$, but there were significantly greater proportions of older-aged people among the non-participants $(P<0.001)$, as reported previously. $^{14}$

An interviewer-administered questionnaire was used to collect socioeconomic and medical information. Data collected include country of birth, marital status, education, occupation, current housing status, as well as lifestyle factors (past and present smoking), eye symptoms, systemic medical, surgical history, etc.

\section{Assessment of dry eye}

Each participant answered a questionnaire on the symptoms of dry eyes. These questions were described previously. ${ }^{14-16}$ They involved questions on feeling of dryness, grittiness, burning sensation, redness, crusting of lashes, and tendency to shut the eyes. The answers were classified into five categories: 'never', 'rarely' (at least once in 3 months), 'sometimes' (at least once in 2-4 weeks), 'often' (at least once a week), and 'all the time' (at least once daily). Symptomatic dry eye or symptoms of tear dysfunction were defined as the presence of at least one symptom that was ranked as 'often' or 'all the time present'. The prevalence rates of symptomatic dry eye in this study sample have been reported recently; ${ }^{17}$ the percentages of people who suffered from dryness, grittiness, burning sensation, redness, crusting, and tendency to shut eyes, often or all the time as $5.4,1.3,1.8,2.7,1.9$ and $0.6 \%$ respectively.

\section{Assessment of visual function}

All the participants underwent an interview using a supplementary questionnaire consisting of 11 questions on vision-related daily living activities that are relevant to the local population of both genders and including near, intermediate and distance visual acuity, and contrast sensitivity. These questions were validated and published elsewhere previously. ${ }^{18,19}$ We assessed difficulties in activities such as navigating stairs, reading road signs, recognizing friends, watching television, reading newspapers, reading small print, driving at night, driving during daytime, cooking, playing chess/ cards, and filling out 4-D or Toto (Lottery) forms. The response options were 'no difficulty', 'a little difficulty', and 'more than a little difficulty' (Supplementary file 1).

Both questionnaires were translated into Malay, and back translated into English by two different interpreters conversant in both the languages. During the questioning, the participant was given a choice to be interviewed in either language. All the interviewers were fluent in both the languages. With the consent of the subject, interviews were randomly recorded for the purposes of quality control.

\section{Assessment of other factors}

All participants were administered a detailed questionnaire and they underwent a physical examination. Data collected included socioeconomic factors (eg, education, occupation), systemic medical history (eg, thyroid eye disease, use of medications), ocular history (eg, previous ocular surgery, previous chemical injury to eye), and lifestyle factors (eg, cigarette smoking).

Presenting and best-corrected visual acuity for each eye were ascertained by Log MAR measurements as previously described. ${ }^{14}$ In cases wherein the two eyes had different presenting visual acuities, the visual function score for the better eye was chosen.

The protocol and ethics used in this study were approved by the Institutional Review Board of the Singapore Eye Research Institute. All study procedures complied with the tenets of the Declaration of Helsinki on human studies.

\section{Data analysis and definitions}

We performed the analysis by comparing the difficulty in performing vision-related daily activities in persons with and without symptomatic dry eyes, both before (crude associations) and after adjusting for various factors. In model 1 we adjusted for age and gender, and in model 2, additionally adjusted for visual acuity in the better eye. 
We repeated the same analyses in subjects who did not have any visual impairment, which was defined by following the WHO definition ${ }^{20}$ All the analyses were performed using SPSS 15.0 for Windows (SPSS Inc, Chicago, IL, USA). Statistical significance was set at the level of $\alpha=0.05$.

\section{Results}

Out of 3280 participants who had dry eye data, $48 \%$ were men. Different numbers of respondents responded to each question on the vision-related activities. The minimum number of respondents to any question was 731 (22\%) and the maximum 3259 (99\%) (Table 1). Presumably, not all subjects participated in any one of the 11 vision-related activities being asked, so they did not respond to all the questions on activities. Out of 2537 participants with no visual impairment, 251 (9.9\%) reported to have symptomatic dry eye.

There was no gender difference among participants who experienced difficulty in reading road signs ( $9 \%$ in men vs $13 \%$ in women) (Figure 1a). Overall, more men drove at night compared with women (867/1576 vs $100 / 1704)$; however, a greater proportion of females $(31 \%$ of those who drove at night) experienced difficulties driving at night compared with men (17\% of those who drove at night) (Figure 1b). This difference was statistically significant $(P=0.0006$ using the chi-square test).

Symptomatic dry eye was found to be significantly associated with difficulty in performing 7 out of 11 vision-related daily activities evaluated in crude analysis (Table 1). After adjusting for age and gender (model 1), or additionally adjusting for visual acuity of the better eye (model 2), symptomatic dry eye was significantly associated with difficulty in performing 7 out of the 11 activities (Table 2, model 2). The higher the number (the odds ratio), the greater the strength of the association. The association was statistically significant (indicated by ${ }^{*}$ ) when the lower limit of the confidence interval exceeded 1.0. These seven activities were navigating stairs (odds ratio $(O R)=1.96,95 \%$ confidence interval (CI): 1.28-3.00), recognizing friends $(\mathrm{OR}=1.99$, 95\% CI: $1.45-2.73)$, reading road signs $(\mathrm{OR}=1.87,95 \% \mathrm{CI}$ : 1.36-2.57), reading newspaper $(\mathrm{OR}=1.50,95 \% \mathrm{CI}$ : 1.11-2.04), watching television $(\mathrm{OR}=1.90,95 \% \mathrm{CI}$ : 1.26-2.87), cooking (OR $=1.94,95 \% \mathrm{CI}: 1.02-3.71)$, and driving at night $(\mathrm{OR}=2.06,95 \% \mathrm{CI}: 1.32-3.21)$.

When all the above analyses were repeated among participants with no visual impairment $(N=2537)$ according to the WHO criteria, these observed associations were essentially unchanged (data not shown).

\section{Discussion}

We found that, in this population-based sample of Southeast Asian Malay persons aged $\geqslant 40$ years in Singapore, symptomatic dry eye was significantly associated with difficulty in performing vision- related daily activities. These are ethnic Malay people who are currently living in Singapore, an island nation located at the tip of the Malay Peninsula within Southeast Asia. Importantly, this impact was independent of visual acuity level. The specific activities that persons with symptomatic dry eye were having difficulty with included navigating stairs, reading road signs, reading newspaper, recognizing friends, watching television, cooking, and driving at night. ${ }^{21}$

Table 1 Association of symptomatic dry eye with difficulty in performing vision related daily activities

\begin{tabular}{|c|c|c|c|c|c|c|c|}
\hline \multirow[t]{3}{*}{ Daily activities } & \multirow{3}{*}{$\begin{array}{c}\text { Total assessed } \\
\mathrm{N}^{\mathrm{a}}\end{array}$} & \multicolumn{5}{|c|}{ Difficulty in performance } & \multirow[t]{3}{*}{$\mathrm{P}^{*}$} \\
\hline & & \multirow{2}{*}{$\begin{array}{c}\text { Symptomatic dry eye } \\
\mathrm{n}\end{array}$} & \multicolumn{2}{|c|}{ No difficulty } & \multicolumn{2}{|c|}{ Difficulty } & \\
\hline & & & $\mathrm{n}$ & $\%$ & $\mathrm{n}$ & $\%$ & \\
\hline Navigate stairs & 3250 & 330 & 299 & 91 & 31 & 9 & 0.001 \\
\hline Read road signs & 3234 & 327 & 269 & 82 & 58 & 18 & $<0.001$ \\
\hline Recognize friends & 3244 & 327 & 266 & 81 & 61 & 19 & $<0.001$ \\
\hline Watch television & 3248 & 329 & 296 & 90 & 33 & 10 & 0.001 \\
\hline Cooking & 2765 & 265 & 253 & 95 & 12 & 05 & 0.026 \\
\hline Playing chess/cards & 729 & 85 & 80 & 94 & 5 & 06 & 0.059 \\
\hline Read newspaper & 2788 & 273 & 207 & 76 & 66 & 24 & 0.003 \\
\hline Filling lottery forms & 2730 & 266 & 216 & 81 & 50 & 19 & 0.113 \\
\hline Reading small print & 2445 & 251 & 172 & 69 & 79 & 31 & 0.055 \\
\hline Driving at daytime & 966 & 116 & 113 & 97 & 3 & 03 & 0.999 \\
\hline Driving at night & 966 & 116 & 80 & 69 & 36 & 31 & $<0.001$ \\
\hline
\end{tabular}

* $P$-value for dry eye, Pearson's chi-square test.

a Total number of participants who performed the activity specified in each row. 
a

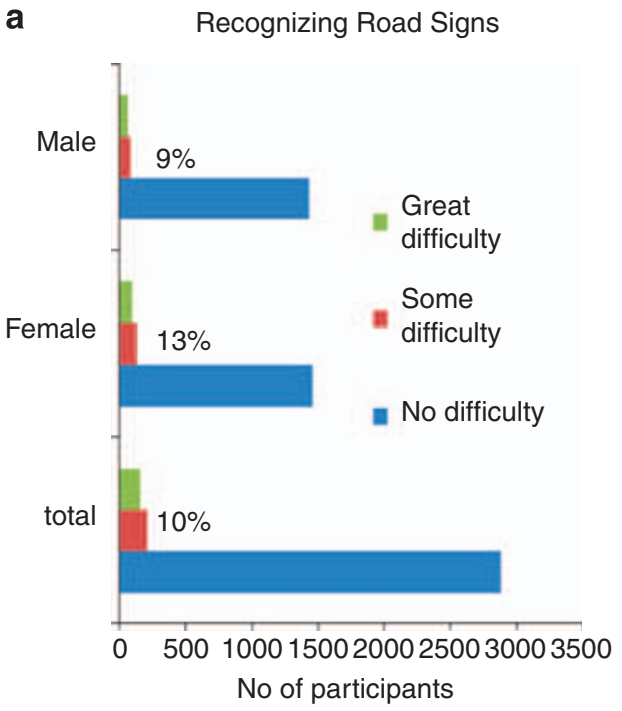

b

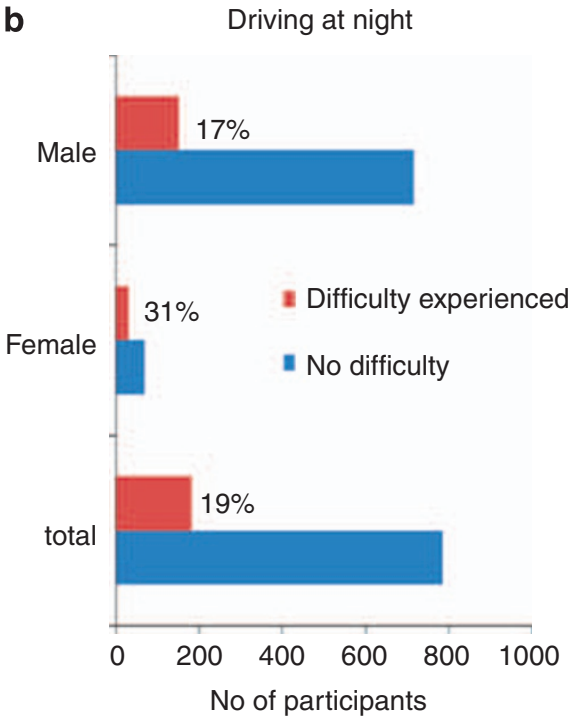

Figure 1 Data showing difficulty in recognizing road signs (a) and driving at night (b). The percentages for difficulty in performing the activities in each subgroup are calculated from the total number of participants in the subgroup who responded to each activity. In (a), the percentages represent the proportion of the participants who had little or great difficulty recognizing road signs, among those who responded to the question on road signs. In (b), the percentages represent the proportion of the participants who had any difficulty in recognizing driving at night, among those who drove at night.

Table 2 Association of symptomatic dry eye with experiencing difficulties in daily tasks after adjusting for age, gender, and visual acuity

\begin{tabular}{lcc}
\hline Daily activities & $\begin{array}{c}\text { OR }(95 \% \text { CI) for experiencing difficulty } \\
\text { in various daily tasks }\end{array}$ \\
\cline { 2 - 3 } & $\begin{array}{c}\text { Adjusted for } \\
\text { age and gender } \\
\text { (model 1) }\end{array}$ & $\begin{array}{c}\text { Adjusted for age, } \\
\text { gender E visual } \\
\text { acuity (model } 2)\end{array}$ \\
\hline Navigate stairs & $2.06(1.37,3.11)^{*}$ & $1.96(1.28,3.00)^{*}$ \\
Read road signs & $1.95(1.43,2.65)^{*}$ & $1.87(1.36,2.57)^{*}$ \\
Recognize friends & $2.08(1.53,2.82)^{*}$ & $1.99(1.45,2.73)^{*}$ \\
Watch television & $2.07(1.39,3.08)^{*}$ & $1.90(1.26,2.87)^{*}$ \\
Cooking & $2.06(1.09,3.89)^{*}$ & $1.94(1.02,3.71)^{*}$ \\
Playing chess/cards & $3.34(1.14,9.78)^{*}$ & $1.94(0.55,6.82)$ \\
Read newspaper & $1.58(1.18,2.13)^{*}$ & $1.50(1.11,2.04)^{*}$ \\
Filling lottery forms & $1.35(0.97,1.88)$ & $1.28(0.92,1.80)$ \\
Reading small print & $1.35(1.01,1.79)^{*}$ & $1.29(0.97,1.72)$ \\
Driving at daytime & $1.01(0.30,3.42)$ & $0.88(0.25,3.08)$ \\
Driving at night & $2.19(1.42,3.39)^{*}$ & $2.06(1.32,3.21)^{*}$ \\
\hline
\end{tabular}

Logistic regression model - dependent variable: no difficulty or presence of difficulty in performing activity; independent variable: presence of symptomatic dry eye.

Model 1: covariates are age and gender; model 2: covariates are age, gender, and presenting visual acuity of the better eye. ${ }^{*} P<0.05$.

Our findings are in keeping with observations from previous studies, largely in clinic samples or trials (Table 3). ${ }^{3}$ For activities in which relatively few persons participated in our sample (for example, only 731 of 3265
Table 3 Comparison of experiencing difficulty in vision-related daily tasks in Singaporean and American population studies

\begin{tabular}{lcc}
\hline Daily activities & $\begin{array}{c}\text { Singapore Malay eye } \\
\text { study (SIMES) }\end{array}$ & $\begin{array}{c}\text { WHS and PHS } \\
\text { study America }\end{array}$ \\
\cline { 2 - 3 } & OR $(95 \%$ CI) & OR (95\% CI) \\
\hline Navigate stairs & $1.96(1.28,3.00)$ & - \\
Professional work & - & $3.49(1.72-7.09)$ \\
Read road signs & $1.87(1.36,2.57)$ & - \\
Recognize friends & $1.99(1.45,2.73)$ & - \\
Watch television & $1.90(1.26,2.87)$ & $2.84(1.05-7.74)$ \\
Reading small print & $1.29(0.97,1.72)$ & - \\
Read newspaper & $1.50(1.11,2.04)$ & $3.64(2.45-5.40)$ \\
Driving at night & $2.06(1.32,3.21)$ & $2.20(1.48-3.28)$ \\
Driving in day & $0.88(0.25,3.08)$ & $2.80(1.58-4.96)$ \\
Cooking & $1.94(1.02,3.71)$ & - \\
Playing chess / cards & $1.94(0.55,6.82)$ & - \\
Buying lottery & $1.28(0.92,1.80)$ & - \\
Computer use & - & $3.37(2.11-5.38)$ \\
\hline
\end{tabular}

participants reported playing chess/cards), the sample size may not be sufficient to enable us to detect statistically significant differences. Differences in some of the daily activities performed by the participants, ethnicity of the participants, and study methodology could explain some discrepancy in findings across studies. ${ }^{3}$ Pooled data from the women's health study and the physicians' health study in the United States, with 690 participants (preponderance of female 
participants), showed that symptomatic dry eye was significantly associated with difficulty in reading, carrying out professional work, using a computer, watching television, and driving during the day and at night, after controlling for age, diabetes, hypertension, and other factors. However, in that study, only three questions, instead of six, were used to assess dry eye symptoms. ${ }^{3}$

Difficulty in performing the above activities may be related to prolonged gazing and reduced blinking due to greater visual demands in performing these activities and exposure to air-conditioning and low-humidity environments, which can result in instability and increased evaporation of the tear film leading to irregularity of the optical refracting surfaces. Previous studies have reported a significant reduction in the blinking rate associated with visual display terminal work, ${ }^{22}$ reading, ${ }^{8}$ and increased driving speed, ${ }^{8,23}$ which can further result in instability of the tear film. Surface irregularity index, a measure of tear film irregularity due to tear instability, increased after sustained eye opening. ${ }^{23}$

The strengths of the present study include its large population-based sample, the first study of this kind conducted in Malay adults, and the use of previously validated questionnaires. ${ }^{18,19}$ Conversely, we had no objective assessment of dry eyes using clinical and laboratory tests ${ }^{16}$ that were performed, because of the logistic difficulties associated with a large population-based study. In particular, selfreported dry symptoms may not only lack of specificity, but are also subject to variability in responses because of different subjective tolerance thresholds. In addition, some symptoms evaluated could be because of ocular surface conditions rather than dry eye, such as Meibomian gland diseases or allergic conjunctivitis. However, if dry eye tests were used, no consensus has been reached regarding the optimal appropriate diagnostic criterion are or combination of criteria. ${ }^{24,25}$ We did not assess certain factors such as wearing of contact lens, ${ }^{26-28}$ LASIK surgery, ${ }^{29}$ keratoplasty $^{12}$ eyelid and conjunctival disease, ${ }^{30}$ allergic conjunctivitis, ${ }^{31}$ seventh nerve palsy, ${ }^{32}$ gout, ${ }^{33}$ total body irradiation, ${ }^{34}$ Sjogren's syndrome, ${ }^{35}$ and participants' compliance with dry eye treatment, ${ }^{36}$ which might be associated with symptomatic dry eye and diminished visual function.

In conclusion, we found that symptomatic dry eye was significantly associated with a reduced ability in performing several important vision-related daily tasks, independent of the actual visual acuity level. Symptomatic dry eye, therefore, has a significant impact on quality of life even in people with good vision.

\section{Summary}

What was known before

- Dry eye is a common eye condition caused by diminished tear production or increased evaporation of tears.

- It is known to affect the quality of vision because of the associated irregularity of the tear film and the optical refracting surfaces.

- The effect of dry eye on daily activities has been a focus of research only recently.

What this study adds

- We report on the impact of symptoms of dry eye or tear dysfunction on specific vision-related daily activities in a large population-based study of Malay adults in Singapore.

- We found symptomatic dry eye significantly associated with difficulty in performing vision-related daily activities, independent of their visual acuity.

- The specific activities that were significantly affected by symptomatic dry eye were navigating stairs, reading road signs, reading newspaper, cooking, recognizing friends, watching television, and driving at night.

\section{Conflict of interest}

The authors declare no conflict of interest.

\section{Acknowledgements}

This study was supported by funding from the National Medical Research Council Grant No. 0796/2003, 0863/2004, and CSI/0002/2005, and the Biomedical Research Council Grant No. 501/1/25-5. Additional support was provided by the Singapore Tissue Network and the Ministry of Health, Singapore.

\section{References}

1 Lemp MA. The definition and classification of dry eye disease: report of the definition and classification subcommittee of the International dry eye workshop. Ocul Surf 2007; 5(2): 75-92.

2 Behrens A, Doyle JJ, Stern L, Chuck RS, McDonnell PJ, Azar DT et al. Dysfunctional tear syndrome: a delphi approach to treatment recommendations. Cornea 2007; 26(7): 901.

3 Miljanović B, Dana R, Sullivan DA, Schaumberg DA. Impact of dry eye syndrome on vision-related quality of life. Am J Ophthalmol 2007; 143(3): 409-415.

4 Sullivan RM, Cermak JM, Papas AS, Dana MR, Sullivan DA. Economic and quality of life impact of dry eye symptoms in women with Sjogren's syndrome. Adv Exp Med Biol 2002; 506(Pt B): 1183-1188.

5 Begley CG, Caffery B, Chalmers RL, Mitchell GL. Dry Eye Investigation (DREI) Study Group. Use of the dry eye questionnaire to measure symptoms of ocular irritation in patients with aqueous tear deficient dry eye. Cornea 2002; 21: 664-670.

6 Asbell PA, Lemp MA. Dry Eye Disease: The Clinician's Guide to Diagnosis and Treatment. Thieme Medical Publishers: New York, 2007. 
7 Goto E, Ishida R, Kaido M, Dogru M, Matsumoto Y, Kojima $\mathrm{T}$ et al. Optical aberrations and visual disturbances associated with dry eye. Ocul Surf 2006; 4(4): 207-213.

8 Goto E, Yagi Y, Matsumoto Y, Tsubota K. Impaired functional visual acuity of dry eye patients. Am J Ophthalmol 2002; 133(2): 181-186.

9 Schiffman RM, Walt JG, Jacobsen G, Doyle JJ, Lebovics G, Sumner W. Utility assessment among patients with dry eye disease. Ophthalmology 2003; 110(7): 1412-1419.

10 Buchholz P, Steeds CS, Stern LS, Wiederkehr DP, Doyle JJ, Katz LM et al. Utility assessment to measure the impact of dry eye disease. Ocul Surf 2006; 4(3): 155-161.

11 Brown MM, Brown GC. Utility assessment and dry eye disease. Ophthalmology 2004; 111(4): 852-853; author reply 853 .

12 Jabbur NS, Sakatani K, O'Brien TP. Survey of complications and recommendations for management in dissatisfied patients seeking a consultation after refractive surgery. I Cataract Refract Surg 2004; 30(9): 1867-1874.

13 Vitale S, Goodman LA, Reed GF, Janine AS. Comparison of the NEI-VFQ and OSDI questionnaires in patients with Sjogren's syndrome-related dry eye. Health Qual Life Outcomes 2004; 2: 44.

14 Foong AW, Saw SM, Loo JL, Shen S, Loon SC, Rosman M et al. Rationale and methodology for a population-based study of eye diseases in Malay people: The Singapore Malay Eye Study (SiMES). Ophthalmic Epidemiol 2007; 14(1): 25-35.

15 Lee AJ, Lee J, Saw SM, Gazzard G, Koh D, Widjaja D et al. Prevalence and risk factors associated with dry eye symptoms: a population based study in Indonesia. Br J Ophthalmol 2002; 86(12): 1347-1351.

16 Lin PY, Tsai SY, Cheng CY, Liu JH, Chou P, Hsu WM et al. Prevalence of dry eye among an elderly Chinese population in Taiwan: the Shihpai Eye Study. Ophthalmology 2003; 110(6): 1096-1101.

17 Tong L, Saw SM, Lamoureux EL, Wang JJ, Rosman M, Tan DT et al. A questionnaire-based assessment of symptoms associated with tear film dysfunction and lid margin disease in an Asian population. Ophthalmic Epidemiol 2009; 16(1): 31-37.

18 Leow BG. Singapore Census of Population 2000: Demographic Characteristics, Statistical Release 1. Department of Statistics: Singapore, 2001.

19 Ecosse LL, Konrad P, Julian T, Saw SM, Wong TY. An evaluation of the reliability and validity of the visual functioning questionnaire (VF-11) using Rasch analysis in an Asian population. Invest Ophthalmol Vis Sci 2009; 50: 2607-2613

20 World Health Organization. International Statistical Classification of Diseases and Related Health Problems, 1st Vol, 10th rev World Health Organization: Geneva, 1992.
21 Schaumberg DA, Sullivan DA, Buring JE, Dana MR. Prevalence of dry eye syndrome among US women. Am J Ophthalmol 2003; 136(2): 318-326.

22 Uchino M, Schaumberg DA, Dogru M, Uchino Y, Fukagawa K, Shimmura $\mathrm{S}$ et al. Prevalence of dry eye disease among Japanese visual display terminal users. Ophthalmology 2008; 115(11): 1982-1988.

23 Singh S, Perel M. Drivers' Perceptions of Headlight Glare from Oncoming and Following Vehicles. National Center for Statistics and Analysis: Springfield, VA, 2003.

24 Lemp MA. Report of the National Eye Institute/Industry workshop on clinical trials in dry eyes. Clao J 1995; 21(4): 221-232.

25 Pflugfelder SC, Solomon A, Stern ME. The diagnosis and management of dry eye: a twenty-five-year review. Cornea 2000; 19(5): 644-649.

26 Nichols J, Sinnott JLT. Tear film, contact lens, and patient-related factors associated with contact lens-related dry eye. Invest Ophthalmol Vis Sci 2006; 47(4): 1319-1328.

27 Nichols JJ, Mitchell GL, Curbow B. Relation between mood and self-reported dry eye in contact lens wearers. Cornea 2006; 25(8): 937-942.

28 Nomura K, Nakao M, Matsubara K. Subjective symptom of eye dryness and lifestyle factors with corneal neovascularization in contact lens wearers. Eye Contact Lens 2004; 30(2): 95-98.

29 Lin YY, Carrel H, Wang IJ, Lin PJ, Hu FR. Effect of tear film break-up on higher order aberrations of the anterior cornea in normal, dry, and post-LASIK eyes. J Refract Surg 2005; 21(5): S525-S529.

30 Vold SD, Carroll RP, Nelson JD. Dermatochalasis and dry eye. Am J Ophthalmol 1993; 115(2): 216-220.

31 Shimmura S, Shimazaki J, Tsubota K. Results of a population-based questionnaire on the symptoms and lifestyles associated with dry eye. Cornea 1999; 18(4): 408-411.

32 Zaidi FH, Gregory-Evans K, Acheson JF, Ferguson V. Familial Bell's palsy in females: a phenotype with a predilection for eyelids and lacrimal gland. Orbit 2005; 24(2): 121-124.

33 Moss SE, Klein R, Klein BE. Prevalence of and risk factors for dry eye syndrome. Arch Ophthalmol 2000; 118(9): 1264-1268.

34 Thomas O, Mahé M, Campion L, Bourdin S, Milpied N, Brunet $\mathrm{G}$ et al. Long-term complications of total body irradiation in adults. Int J Radiat Oncol Biol Phys 2001; 49(1): 125-131.

35 Fox RI, Howell FV, Bone RC, Michelson P. Primary Sjogren syndrome: clinical and immunopathologic features. Semin Arthritis Rheum 1984; 14(2): 77-105.

36 Yazdani C, McLaughlin T, Smeeding JE, Walt J. Prevalence of treated dry eye disease in a managed care population. Clin Ther 2001; 23(10): 1672-1682.

Supplementary Information accompanies the paper on Eye website (http://www.nature.com/eye) 